\title{
Revaluating the relationship between keratoplasty and intraocular lenses
}

\author{
Jesse Panthagani $\mathbb{1}^{1} \cdot$ Ankur Barua $^{1}$
}

Received: 7 March 2020 / Accepted: 11 March 2020 / Published online: 15 April 2020

(c) The Royal College of Ophthalmologists 2020

We read the article published this month with interest and raising awareness of this concern should be relevant to all specialists and not just those with an interest in corneal disease.

The treatment for corneal endothelial pathology has altered over time from full thickness corneal transplantation (first performed in 1905 by Zirm) [1], posterior lamellar keratoplasty techniques (performed by Melles in 1998) [2] to recent advances where Descemet's membrane (DM) and endothelium were stripped from the host cornea (descemetorrhexis) and replaced with a donor button consisting of posterior stroma, DM and endothelium-Descemet's stripping endothelial keratoplasty—clinical results published first by Price in 2006 [3]. Transition has now occurred from microkeratome donor dissection - termed (ultrathin) Descemet stripping automated endothelial keratoplasty (DSAEK) [4], to Melles' technique involving only donor DM and endothelium being transplanted-termed Descemet's membrane endothelial keratoplasty in 2006 (DMEK) [5].

Penetrating keratoplasty to DS(A)EK to DMEK has allowed progressively better visual outcome, less corneal astigmatism and rapid visual recovery [6]. DMEK has been shown to provide better visual outcomes compared to DSAEK [7] with the advantage of a smaller incision (2.4 versus around $5 \mathrm{~mm}$, respectively) [8]. The donor graft preparation for DMEK can be challenging and there is evidence to show that there is an increased risk of rebubbling compared to DS(A)EK [9].

Risks of endothelial keratoplasty (EK) include but are not limited to graft dislocation, failure, rejection, interface opacification, pupillary block, cystoid macular oedema, and epithelial ingrowth $[6,10]$. Most common adverse events do

Ankur Barua

barua.ankur@gmail.com

1 Birmingham and Midland Eye Centre, 76 Dudley Road, Birmingham B18 7QH, UK not impact the long-term visual outcome [10], but there has been growing evidence of hydrophilic intraocular opacification (IOL) following DSAEK and more recently with DMEK surgery (Table 1).

Intraocular gas injection has been routinely used in vitreoretinal surgery for around 4 decades, and similarly in the last 2 decades for EK. Due to the risk of rebubbling, some surgeons prefer to use sulfur hexafluoride (SF6) 16-20\% to allow for a longer period of tamponade of the graft. There have been concerns about use of intraocular long acting gases such as SF6 or perfluoropropane (C2F6) causing an increase in intraocular pressure during nitrous oxide anaesthesia [11], or during changes in atmospheric pressure. Furthermore, it is important that the recipient base is smooth without any residual DM so again some surgeons do a larger area of descemetorrhexis and ensure the DM is stripped without any agitation of the overlying posterior stroma. Some surgeons may do this under air. With the higher risk of rebubbling, there is a higher risk of IOL opacification [12].

IOL opacification is thought to be from calcium phosphate deposits on the surface or just within the substance of the lens $[13,14]$. Several mechanisms are thought to play a role in IOL opacification. Potential changes in the metabolic composition of the aqueous humour are thought to occur the presence of exogeneous gas and an exacerbated inflammatory reaction due to multiple surgeries [15]. Dehydration of the hydrophilic IOL may affect the surface that encourages the formation of crystallisation nuclei [14]. UV exposure has also been postulated to play a part with the typical findings of IOL calcification seen centrally with the periphery of the IOL protected by the iris [16].

Implementing a new technique within hospital services requires an analysis of the potential risks associated and one major factor is the use of hydrophilic intraocular lenses. The implications would be for patients needing EK who previously had cataract surgery and furthermore determining what type of IOL was used. Whether a hydrophilic lens was used, or the IOL type could not be found, the patient should 


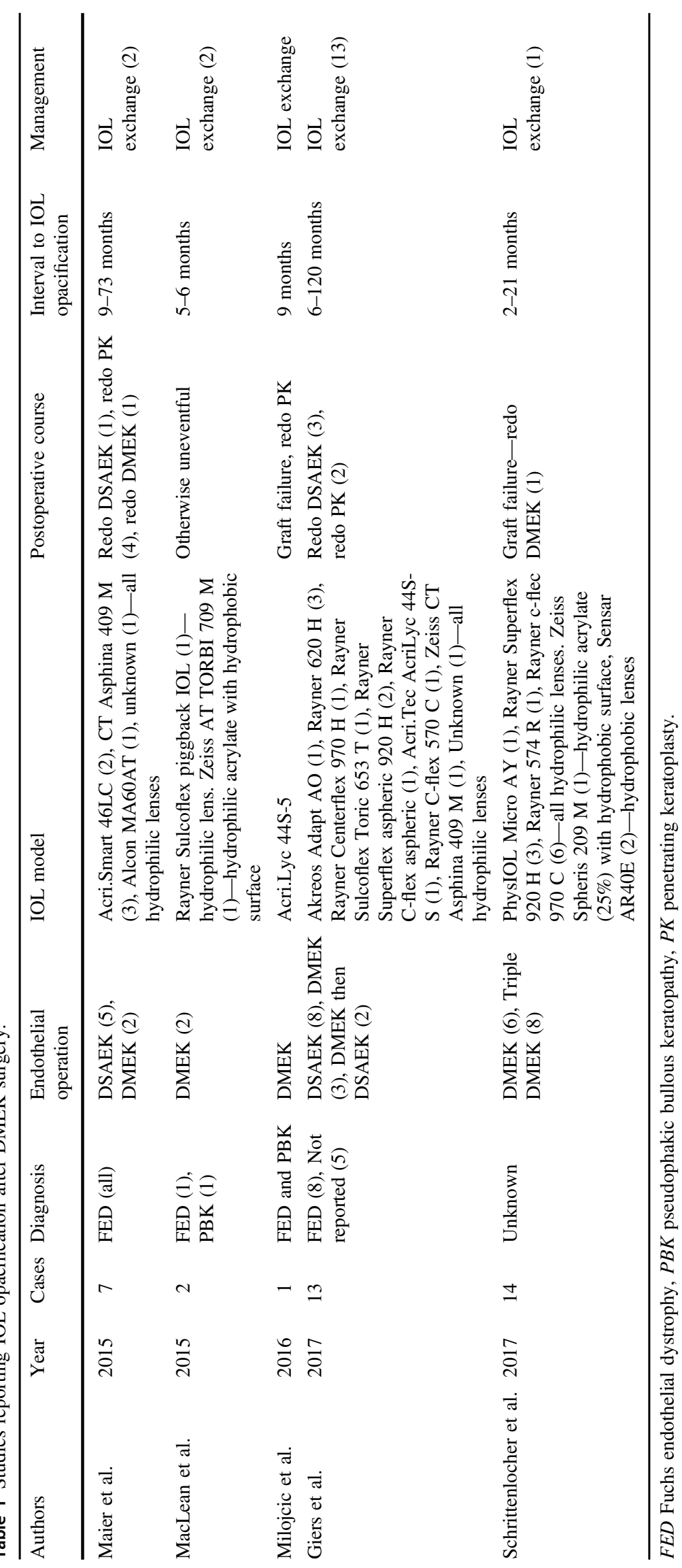


be made aware of the risk regardless. The next issue would be for phakic patients who need endothelial surgery with cataract, especially in the situation where the standard IOL used is hydrophilic. This would require either a robust IOL ordering system or a hydrophobic lens bank in place.

Identification of opacification in patients can be difficult, and management complicated further if already treated with YAG capsulotomy. The process of IOL exchange with hydrophilic lenses may pose less of a challenge than other types of lenses due to the malleability of the lens substance allowing smaller incision surgery, but with a corneal graft in place there are other specific risks to consider when doing a lens exchange in EK patients. This includes damage to the endothelium during IOL removal, detachment of graft during surgery, and increased risk of rejection and failure of the graft post-surgery. The endothelial cell count may have to be considered before surgery and the patient counselled for potential need for further corneal surgery. Damage to the capsular bag and potential loss of vitreous may then result in need for a larger wound, different IOL choice and longer surgery which would have implications on the graft survival. IOL exchange can be a very challenging procedure which is made more challenging with a graft in place.

How do we address this? To minimise any risk, hydrophobic lenses should be used where possible in those with any corneal disease. I try to use hydrophobic lenses in all patients with corneal disease potentially needing a corneal graft in the future. If a patient needs a redo graft from endothelial failure, a DMEK may be an excellent option depending on the clarity and astigmatism in the current PK. If the patient has keratoconus and may need a DALK procedure in the future, there is the risk air may be needed in a microperforation of the Descemet's. Therefore, if the patient needs cataract surgery prematurely for some other reason a hydrophobic lens would be preferable. These are some examples but with the transition towards replacing solely the diseased corneal tissue, partial thickness corneal transplant is preferable and intracameral air or gas injection may be required.

Hydrophilic IOL opacification from calcium phosphate accumulation has not been restricted to just one manufacturer or company. Despite being relatively rare, there have been certain batches or manufacturers who have had more incidences, but there seems to be a specific increased risk in those patients who have had air or gas injection into the anterior chamber. Whereas once the incidence was thought to be in the order of $1 \%$, there are suggestions from various papers that this may have increased since the advent of EK to between 5 and $10 \%$ which is a substantial risk $[17,18]$. Other substances have been found to cause a similar opacification pattern, such as use of recombinant tissue plasminogen activator [19].
The incidence may be actually higher than first thought as EK is mainly carried out in older patients; and as this is often a late complication some opacification may go unnoticed. Similar papers have shown an increased incidence in intravitreal gas injection patients [20]. IOL dehydration is thought to be the main concern expressed by the manufacturers.

It is important to give the patient the best possible longterm outcome, and to make sure they are fully informed of specific concerns such as the presence of a hydrophilic lens. However, with the increasing evidence we have now and the awareness that intracameral injection of exogenous material such as gas or air is an increased risk, any patients who (may) need EK in the future should have a hydrophobic IOL on principle. It would be difficult to address this completely, as pseudophakic bullous keratopathy or endothelial damage may not be predicted to need corneal surgery until after cataract surgery has occurred, and may have had a hydrophilic lens.

As a conclusion, the increased awareness of this problem is important, and precautions must be taken to minimise the need for further surgery. If there is a known hydrophilic IOL in the eye, and the patient needs intracameral gas insertion, there may in the future be a way of protecting the surface of the IOL with a dissolvable intracameral lens while the gas is in place or some equivalent development. The question of ultrathin DSAEK vs DMEK may also be analysed with a hydrophilic lens in place-with lower rebubbling rates in DSAEK and often just a need for air rather than gas, this may be a reason to choose DSAEK over DMEK if the risk of rebubbling is less. However, if opacification develops a fully attached and clear DMEK may fair better with less risk of detachment than a fully attached DSAEK.

\section{Compliance with ethical standards}

Conflict of interest The authors declare that they have no conflict of interest.

Publisher's note Springer Nature remains neutral with regard to jurisdictional claims in published maps and institutional affiliations.

\section{References}

1. Zirm EK. Eine erfolgreiche totale keratoplastik (a successful total keratoplasty). Refract Corneal Surg. 1906;5:258-61.

2. Melles GR, Eggink FA, Lander F, et al. A surgical technique for posterior lamellar keratoplasty. Cornea. 1998;17:618-26. https:// doi.org/10.1097/00003226-199811000-00010

3. Price FW, Price MO. Descemet's stripping with endothelial keratoplasty in 50 eyes: a refractive neutral corneal transplant. J Refract Surg. 21:339-45. 
4. Gorovoy MS. Descemet-stripping automated endothelial keratoplasty. Cornea. 2006;25:886-9. https://doi.org/10.1097/01.ico. 0000214224.90743 .01

5. Melles GRJ, Ong TS, Ververs B, van der Wees J. Descemet membrane endothelial keratoplasty (DMEK). Cornea. 2006;25:987-90. https://doi.org/10.1097/01.ico.0000248385.16896.34

6. National Institute for Health and Care Excellence (2009). Corneal endothelial transplantation. https://www.nice.org.uk/Guidance/ IPG304. Accessed 3 Mar 2020.

7. Guerra FP, Anshu A, Price MO, Price FW. Endothelial keratoplasty: fellow eyes comparison of Descemet stripping automated endothelial keratoplasty and Descemet membrane endothelial keratoplasty. Cornea. 2011;30:1382-6. https://doi.org/10.1097/ ICO.0b013e31821ddd25

8. Veldman PB, Terry MA, Straiko MD. Evolving indications for Descemet's stripping automated endothelial keratoplasty. Curr Opin Ophthalmol. 2014;25:306-11. https://doi.org/10.1097/ICU. 0000000000000073

9. Price MO, Giebel AW, Fairchild KM, Price FW. Descemet's membrane endothelial keratoplasty: prospective multicenter study of visual and refractive outcomes and endothelial survival. Ophthalmology. 2009;116:2361-8. https://doi.org/10.1016/j.ophtha. 2009.07.010

10. Lee WB, Jacobs DS, Musch DC, et al. Descemet's stripping endothelial keratoplasty: safety and outcomes: a report by the American Academy of Ophthalmology. Ophthalmology. 2009;116:1818-30. https://doi.org/10.1016/j.ophtha.2009.06.021

11. The Royal College of Ophthalmologists (2018). Ophthalmic safety alert-do not use nitrous oxide when there is gas in an operated eye. https://www.rcophth.ac.uk/2018/12/ophthalmic-sa fety-alert-use-of-nitrous-oxide-when-there-is-gas-in-an-operatedeye/. Accessed 3 Mar 2020.

12. Schrittenlocher S, Penier M, Schaub F, et al. Intraocular lens calcifications after (triple-) descemet membrane endothelial keratoplasty. Am J Ophthalmol. 2017;179:129-36. https://doi.org/ 10.1016/j.ajo.2017.04.024

13. MacLean KD, Apel A, Wilson J, Werner L. Calcification of hydrophilic acrylic intraocular lenses associated with intracameral air injection following DMEK. J Cataract Refract Surg. 2015;41:1310-4. https://doi.org/10.1016/j.jcrs.2015.05.006

14. Giers BC, Tandogan T, Auffarth GU, et al. Hydrophilic intraocular lens opacification after posterior lamellar keratoplasty - a material analysis with special reference to optical quality assessment. BMC Ophthalmol. 2017;17:150. https://doi.org/10.1186/ s12886-017-0546-8

15. Milojcic C, Latz C, Tandogan T, et al. Eintrübung einer hydrophilen acryl-Intraokularlinse nach DMEK. Der Ophthalmol. 2017;114:832-7. https://doi.org/10.1007/s00347-016-0394-6

16. Werner L. Causes of intraocular lens opacification or discoloration. J Cataract Refract Surg. 2007;33:713-26. https://doi.org/10. 1016/j.jcrs.2007.01.015

17. Ahad MA, Darcy K, Cook SD, Tole DM. Intraocular lens opacification after descemet stripping automated endothelial keratoplasty. Cornea. 2014;33:1307-11. https://doi.org/10.1097/ICO. 0000000000000279

18. Nieuwendaal CP, van der Meulen IJE, Patryn EK, et al. Opacification of the intraocular lens after descemet stripping endothelial keratoplasty. Cornea. 2015;34:1375-7. https://doi.org/10.1097/ ICO.0000000000000574

19. Fung SSM, Sykakis E, Islam NM, et al. Intraocular lens opacification following intracameral injection of recombinant tissue plasminogen activator to treat inflammatory membranes after cataract surgery. J Ophthalmol. 2015;2015:975075. https://doi. org/10.1155/2015/975075

20. Marcovich AL, Tandogan T, Bareket M, et al. Opacification of hydrophilic intraocular lenses associated with vitrectomy and injection of intraocular gas. BMJ Open Ophthalmol. 2018;3: e000157. https://doi.org/10.1136/bmjophth-2018-000157 